\title{
Patient Experiences of Medical Screening Performed by the Dental Services: A Qualitative Study
}

\author{
Göran Friman $^{1,2^{*}}$, Ghazaleh Golestani ${ }^{3}$, Awara Kalkali ${ }^{4}$, Inger Wårdh ${ }^{1}$, Margareta Hultin ${ }^{5}$ \\ ${ }^{1}$ Department of Dental Medicine and Academic Centre of Gerodontics, Karolinska Institutet, Stockholm, Sweden \\ ${ }^{2}$ Department of Health and Environmental Sciences, Karlstad University, Karlstad, Sweden \\ ${ }^{3}$ The Swedish Dental Service Organizations, Stockholm County AB, Stockholm, Sweden \\ ${ }^{4}$ The Swedish Dental Service Organizations Västra Götaland, Gothenburg, Sweden \\ ${ }^{5}$ Department of Dental Medicine/Division of Periodontology, Karolinska Institutet, Huddinge, Sweden \\ Email: "goran.friman@ki.se
}

Received 30 October 2013; revised 1 December 2013; accepted 13 December 2013

Copyright (c) 2013 Göran Friman et al. This is an open access article distributed under the Creative Commons Attribution License, which permits unrestricted use, distribution, and reproduction in any medium, provided the original work is properly cited.

\begin{abstract}
Objective: To explore how medical screening performed by the dental service was perceived from the patient's perspective. Material and methods: Medical screening for high blood pressure and high plasma glucose was performed on 170 patients at a dental clinic in a small town in central Sweden. Seventeen individual interviews were conducted with a strategic sampling of these patients. The interviews were recorded and transcribed. The transcriptions were coded and categorized in a manifest analysis, followed by a latent, interpretive analysis. Results: The manifest analysis resulted in three categories: Positive attitude to screening and dental professionals which need to have specific knowledge of medical screening; Dental care which provides continuity but is not a neutral environment; and Feedback on the medical screening results and desired cooperation between dental and health care services. The latent analysis pointed out the importance of the patient's feeling that the procedure is carried out properly and safely, and requests for clear feedback concerning the results of the screening. Conclusions: The interviewees experienced the dental care service as providing continuity. They would like to have regular medical screenings at their regular dental appointments to identify risks of cardiovascular diseases and diabetes. However, they expressed that it was important for the dental care staff to have the necessary medical knowledge. They also wanted good cooperations between the dental and health care services, with clear feedback to the patients about both positive and negative results and, when appropriate, referrals to the health care service.
\end{abstract}

*Corresponding author.
Keywords: Diabetes; Hypertension; Medical Screening; Patient Satisfaction; Risk Assessment

\section{INTRODUCTION}

Many individuals have undiagnosed type 2 diabetes [1,2] or undiagnosed hypertension without symptoms [3]. Diagnoses are often not recognized until complications arise [4].

One third of individuals with type 2 diabetes are undiagnosed [2,5]. Even in a pre-diabetic condition, there is an increased risk of complications such as cardiovascular disease. Early diagnosis is important for successful and cost-effective treatment [6].

Hypertension, a global problem, was noted in $26.4 \%$ of the adult population in 2000 and is predicted to increase by about $60 \%$ in 2025, from 972 million to 1.56 billion [7], with ischemic heart disease and cerebrovascular disease being the leading causes of death worldwide [8]. Both diabetes and cardiovascular disease show correlations to oral health, in particular periodontal disease $[9,10]$.

In many countries, dentists follow their patients on a regular basis. In 2010-2011, 72.7\% of the adult Swedish population had dental appointments [11]. Among Swedes aged 50 and above, 81\% reported having seen a dentist in the preceding year, data from 2007 [12].

This opportunity to identify both oral and general risk factors explains why medical screening has recently been introduced and recommended in dentistry $[13,14]$. In a quantitative study of patient experiences, all the respondents expressed a favourable attitude to chair-side screening [15]. However, to our knowledge no qualitative studies have been performed concerning medical screening for both blood pressure and plasma glucose, but for 
diabetes screening only [16].

In a small town in central Sweden, medical screening for blood pressure and plasma glucose was offered consecutively to 207 regular adult dental patients at their annual check-up, of whom 170 agreed to participate. Thirty-nine patients were referred to health care as possibly at risk of hypertension or diabetes, and 24 of these received further medical treatment or lifestyle recommendations [17].

The aim of the present study was to explore how this medical screening was perceived from the patient's perspective.

\section{MATERIAL AND METHODS}

\subsection{Ethics Statement}

The study is approved by the Regional ethical review board in Uppsala, Sweden, in accordance with the ethical standards and with the Helsinki Declaration of 1975, as revised in 1983. The participants received both verbal and written information about the study and that they were not compensated for their time, all of them gave their written informed consent to participate sent by post.

\subsection{Procedure}

This qualitative study was based on individual interviews. It was conducted from March to May 2010 in a neutral venue not adjacent to the dental clinic in the town where the medical screening was performed.

Twenty-eight patients who underwent medical screening at the dental clinic in addition to their dental examination were asked in a personal letter to participate in an individual interview. They were selected strategically to maximize the variety of data in terms of age, gender, professional background and results of the medical screening.

The interviews were conducted by one of the authors (AK) with open-ended questions from an interview guide focusing on two main areas:

- How did the patients experience medical screening performed by dental professionals?

- How do the patients perceive regular medical screening when integrated into the regular dental examination?

The study process was inspired by Grounded Theory and the interviewees were asked to freely describe their experiences and opinions in conversational style [18]. When necessary, the interviewer asked additional questions for clarification. The interviews lasted approximately 25 - 40 minutes and were audio taped and transcribed verbatim by another author (GG). The transcription process was successively performed in the same order as the interviews. This procedure made it possible to check whether the interview guide or the interviews needed to be supplemented [18]. After 17 interviews, the authors concluded that no new relevant information emerged, saturation was reached [18] and the data collection ended.

\subsection{Analysis}

As the study material did not have the prerequisites to entirely follow the Grounded Theory method, data was treated like a model similar to qualitative manifest and latent content analysis [19]. The interview texts were read in their entirety by the authors and divided into groups of meaning-bearing units, codes. Similar codes were merged and then sorted into subcategories and categories. A comparison was made with the interview guide to see if the categories corresponded to the question areas. This represented the manifest level of analysis. Then the authors looked for a main category or a theme, the latent content analysis.

The analysis was illustrated with quotations. The quotes presented in this article are typical of the views expressed by the interviewees and are used to exemplify the categories and theme.

\section{RESULTS}

Of the 28 selected potential interviewees, 19 agreed to participate. The reasons for not participating were: three were "out of town", three "forgot how the screening was conducted" and three did not reply. Two of the participants then failed to appear for the agreed interview: one had decided not to participate in the study and the other failed to appear for the interview and then could not be reached either by phone or letter. Seventeen patients were ultimately interviewed (Table 1).

Meaning-bearing units were extracted from the texts, and codes, subcategories and categories were formed (Table 2). Figure 1 gives a visual presentation of the findings. The analysis revealed three categories made up of a number of subcategories. One theme permeated

Table 1. Characteristics of study material. Values are number of participants if not otherwise stated.

\begin{tabular}{lcc}
\hline Study material & $\begin{array}{c}\text { Medical screening } \\
\text { N (\%) }\end{array}$ & $\begin{array}{c}\text { Interview } \\
\mathbf{n ~ ( \% )}\end{array}$ \\
\hline Samples & 207 & 28 \\
Dropouts & 37 & 11 \\
Participants & $\mathbf{1 7 0 ( 1 0 0 )}$ & $\mathbf{1 7}(\mathbf{1 0 0 )}$ \\
Men & $76(44.7)$ & $9(52.9)$ \\
Women & $94(55.3)$ & $8(47.1)$ \\
Mean age & 63.95 & 66.05 \\
Referred for health care & $40(23.5)$ & $7(41.2)$ \\
Required health care or & $23(13.5)$ & $4(23.5)$ \\
lifestyle recommendations & & \\
\hline
\end{tabular}


Table 2. Examples of meaning-bearing units, codes, subcategories and categories.

\begin{tabular}{|c|c|c|}
\hline Codes & Subcategory & Category \\
\hline \multicolumn{3}{|l|}{$\begin{array}{l}\text { Codes and subcategories describing the category "Positive } \\
\text { attitude to screening but dental professionals need to have } \\
\text { specific knowledge of medical screening" }\end{array}$} \\
\hline $\begin{array}{l}\text { Positive view on screening } \\
\text { Prevent potential noncommunicable diseases } \\
\text { Insight into a possible link between general and oral health }\end{array}$ & Positive attitude to screening & $\begin{array}{l}\text { Positive attitude to screening but dental } \\
\text { professionals need to have specific } \\
\text { knowledge of medical screening }\end{array}$ \\
\hline $\begin{array}{l}\text { Equal sampling standard by health care as by and dental } \\
\text { professionals } \\
\text { Similar education and training }\end{array}$ & Professional skills in medical screening & \\
\hline \multicolumn{3}{|l|}{ Requires proper knowledge } \\
\hline Prepared to pay the same for the service & Willingness to pay & \\
\hline $\begin{array}{l}\text { Dental regularity and continuity } \\
\text { Different doctors, usually the same dental professional }\end{array}$ & Dental care provides continuity & $\begin{array}{l}\text { Dental care provides continuity but is } \\
\text { not a neutral environment }\end{array}$ \\
\hline \multicolumn{3}{|l|}{ Reluctance to seek medical attention } \\
\hline $\begin{array}{l}\text { White coat hypertension } \\
\text { Dental fear }\end{array}$ & $\begin{array}{l}\text { Risk of erroneously high blood pressure in } \\
\text { the dental environment }\end{array}$ & \\
\hline \multicolumn{3}{|l|}{$\begin{array}{l}\text { Codes and subcategories describing the category "Feedback } \\
\text { about the medical screening results and desired cooperation } \\
\text { between dental and health care services" }\end{array}$} \\
\hline Getting a response about their health & $\begin{array}{l}\text { Feedback about the medical screening } \\
\text { results }\end{array}$ & $\begin{array}{l}\text { Feedback about the medical screening } \\
\text { results and desired cooperation between } \\
\text { dental and health care services }\end{array}$ \\
\hline \multicolumn{3}{|l|}{ Referral to health care } \\
\hline Collaboration or integration between dental and health care & & \\
\hline Dental professional cannot make a medical diagnosis & & \\
\hline
\end{tabular}

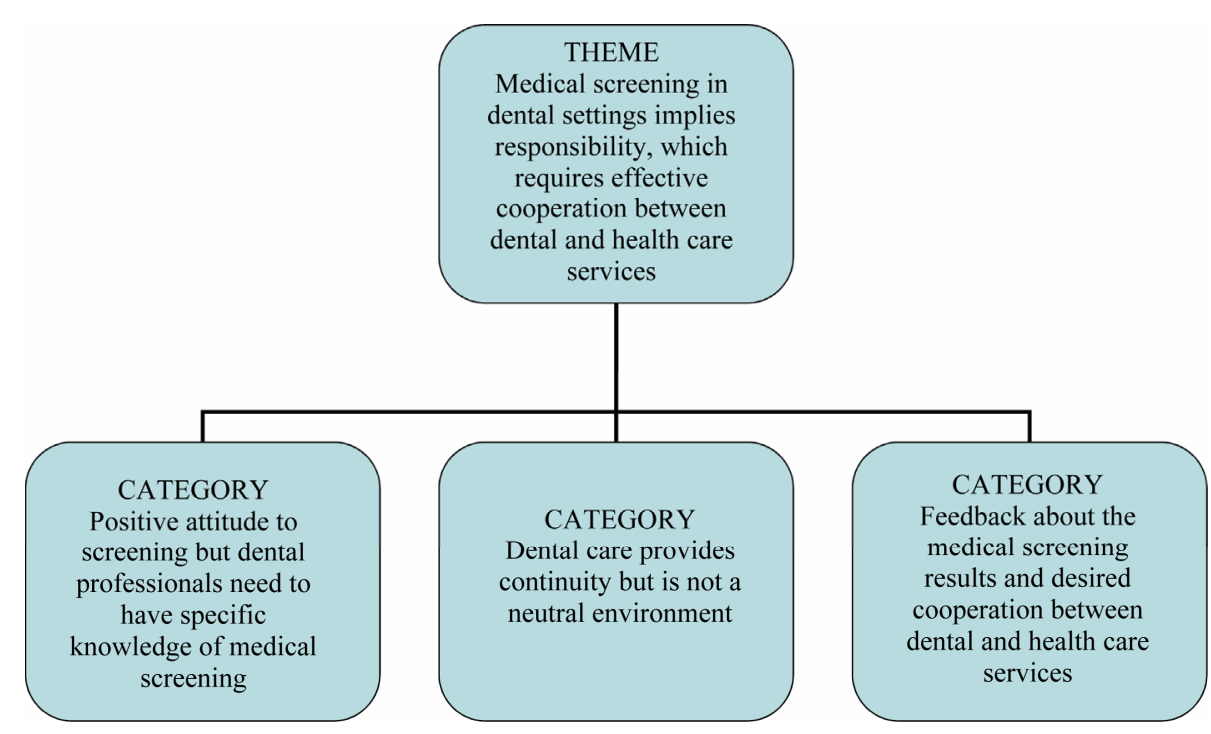

Figure 1. Patient experiences of medical screening performed by the dental care service, as described in three categories and one theme. 
them all. Below, these results are presented in greater detail.

\subsection{Manifest Analysis}

Positive attitude to screening but dental professionals need to have specific knowledge of medical screening

This category included the subcategories "positive attitude to screening", "professional skills in medical screening" and "willingness to pay".

All interviewees had positive thoughts and opinions about undergoing medical screening at a dental clinic. Some also had some insight into a possible relationship between general health and oral health, which made them even more interested in a screening.

It's good that the dentist does a medical screening since there may be a relationship between the two. And I guess there's something to the idea that teeth and things affect the rest of one's body. If medical screening can prevent diseases and injuries in time, that's definitely an advantage.

The interviewees felt it was important for the dental care staff to have adequate knowledge if they were going to do medical screening, and also stated that there was no difference between dental and health care staff when it came to the practical performance of the screening.

Actually I thought they were just as professional as at the doctor's office. I didn't experience any difference. In my opinion, he has, I guess, as I see it, they are basically trained in similar ways.

The interviewees were willing to pay for this service. Since they paid at the health care service, they could just as well pay the same at the dental care service.

I don't mind paying, since I uh, go to the health center and then I have to go there. And pay for it. So uh, if the price is the same.

Dental care provides continuity but is not a neutral environment

This category included the subcategories "dental care provides continuity" and "risk of erroneously high blood pressure in the dental environment".

Many interviewees remarked that they go to their dentist yearly, and usually see the same dentist, so they go there more often than to the doctor, which made medical screening by the dental service seem convenient.

You always see a different doctor, but usually the same dentist. I think lots of people go to the dentist more regularly than to the doctor.

The advantages of dental regularity and continuity were stressed by several interviewees, who pointed out that some people are reluctant to seek medical attention. They neglect their symptoms. Dental care can help identify patients at risk with this screening.

I go to the dentist more often than the doctor. So this is a good way for me to get checked, you might say.
On the other hand I would be glad to have it discovered in time because then I would actually be able to do something about it.

Some of the interviewees mentioned that it was important for the dental services to consider source of error in blood pressure sampling. They pointed out an uncertainty in pressure measurement when they had a high value at the clinic but a normal value when their blood pressure was taken at home or after rest at the health center. Some interviewees could not remember any period of rest before their blood pressure was taken, but said that it was just the same as at the doctor's office.

When they take your blood pressure when you are there to see the dentist and are a little nervous, then it will be higher. That's a natural reaction. In fact it always goes up when you are the dentist's or the doctor's office. It would go up a little bit in any case.

Feedback about the medical screening results and desired cooperation between dental and health care services

This category included the subcategories "feedback about the medical screening result", and "integrated dental and health care".

The interviewees emphasized the importance of getting a response about their health through feedback after the screening. They pointed out that if medical screening were included in the annual dental appointment, it would be important to receive feedback.

Well, nothing happened afterwards. So I think that was one thing, getting no follow-up. I don't know what happened. If I had had high blood glucose I don't know if there would have been follow-up, either.

It was not clear to everyone as to whether there was established collaboration between the dental and health care services. Therefore, many interviewees pointed out such collaboration needed to be established before medical screening in dental settings could be introduced, and they even suggested integration between dental and health care.

I don't really understand why there is a distinction between the health care and dental services.

If plasma glucose and blood pressure are checked by the dental care services, this should certainly make things easier for the health care staff and if necessary, the dental care service can send a referral to health care so the patient gets a new health care contact. In other words, the dental care services become a link. The interviewees considered that close collaboration was especially beneficial when disease symptoms are neglected.

Well, I think I'd get help faster with a referral. It would be sent to my doctor, like. Which would make things happen better than if I tried to work it out myself.

I'd see it as a good thing if they sent a referral-directly...of course there may be people who...would 
rather themselves...make the contact but I don't see... any disadvantage about it.

Not all but most of the interviewees were aware that the dental care services cannot make a medical diagnosis.

\subsection{Latent Analysis}

Medical screening in dental settings implies responsibility, which requires effective cooperation between the dental and health care services

The latent analysis revealed that introducing medical screening in a dental care setting is a responsibility that requires good collaboration between the dental and health care services. Some interviewees in this project felt that the collaboration was not completely clear to them.

When the patient's screening values exceeded thresholds for disease risk, these at-risk patients would have the opportunity, if the dental care service referred them to the health care service, to receive health care earlier without having to contact the health care service themselves. The referral would result in a smoother and easier handling of their cases. However, it was important to the interviewees to experience the procedure as being carried out properly and safely.

Some interviewees pointed out a feeling of insecurity in the lack of feedback and information about their test results. Many felt that they were not informed whether they had elevated values. All interviewees requested clear feedback if a medical screening were to be introduced in the dental care. Others realized that they probably would have been notified if they were at risk of disease.

When they did the diabetes test I thought, uh, well, if they found anything I do hope they would call and tell me. Yes, and that there has to be a link to the health centre or something, with the dentist.

Finding out that you are at risk of disease or possibly already have a disease was not negative, according to the interviewees. They all felt it didn't matter whether this information came from the dental or medical services. The most important thing was that they found out. All interviewees realized that medical screening could lead to early disease detection.

There can't be anything negative about finding out that you're sick.

The attitude of the interviewees to the dental care services taking responsibility for their general health was positive, and they pointed out benefits of undergoing medical screening at the dentist's office. However, one person out of the seventeen felt that this was not the responsibility of the dental service.

\section{DISCUSSION}

In the present study, it was revealed that all interviewees had a generally positive attitude to undergoing medical screening as part of their regular dental examinations. Dentists' attitudes to medical screening as a part of the dental examination have also been reported to be positive $[16,20]$.

\subsection{Method Discussion}

It is important to achieve trustworthiness in a qualitative study [19]. Both authors GF and IW have completed education in qualitative methodology and IW has experience from conducting several qualitative studies. To assure credibility [19], the interviewer in the present study was a person unknown to the participants and the interviews were conducted in a neutral venue not adjacent to the dental clinic.

There was a strategic selection of participants and the sampling continued until the authors concluded that no new information emerged, although there were very few negative comments from the interviewees. The dental clinic at which the screening was carried out has individualized prophylactic care programs, and some interviewees may have been informed in that context about possible relationships between oral health and general health. All interviewees had previously agreed to undergo medical screening. These factors and the fact that some of the interviewees were referred to the health care services after the medical screening, where they were given further treatment and/or lifestyle recommendations, may have helped them to understand the benefits of the process of medical screening. It is possible that some of the individuals who declined to participate might have had a negative attitude about medical screening. Another choice of method, for example an anonymous postal questionnaire to all those who participated in the screening, might have been more effective at capturing negative attitudes [15].

The researchers made their analyses as quickly as possible after the data collection to minimize the risk of changes in the researchers' interpretations, to increase the dependability [19]. After each interview, the interview process was evaluated to secure relevant data for the next interview.

Accurate written description of the research process and the context was made to pursue transferability [19] and to give the reader the ability to evaluate whether these findings are transferable to other contexts.

\subsection{Result Discussion}

All but one of the interviewees in this study was positive to the procedure with medical screening in dental settings and was willing to pay for this service. They appreciated the continuity the dental services provide and expressed some dissatisfaction with the absence of such 
continuity in Swedish health care. Similar positive results are revealed in qualitative studies of patients' attitudes toward diabetes or HIV testing in dental settings $[16,21]$. A questionnaire study among adults with diabetes in Great Britain [22] revealed that 53.5\% of the participants supported dentists' involvement in diabetes screening and that $20.9 \%$ would be willing to pay for diabetes screening in a dental setting. In the opinion of the authors, this relatively low interest in medical screening in Great Britain may be attributable to poor awareness of the importance of oral self-care and limited awareness of the oral health complications associated with diabetes.

Our interviewees can be regarded as quite well informed about both oral and general health. They had formulated demands and expectations if medical screening were to be introduced in dental care and thought it was self-evident that a dentist has a responsibility to have adequate medical knowledge before undertaking such testing. Dentists have requested training and information about practical procedures if medical screening is introduced [20]. Well-established cooperation with the health care services is equally important for optimal management of patients after screening. It was especially pointed out by several of the interviewees as a major advantage that the dental service provides this contact in the form of a written referral in case of exceeded threshold values. This is the responsibility of the dental service, but dentists are not qualified to make medical diagnoses. The aim of medical screening performed by the dental care service is to identify patients at risk.

As pointed out by the interviewees, this kind of screening could result in false positive results concerning high blood pressure because of "white coat syndrome" in a somewhat intimidating dental environment. This could lead to both unnecessary appointments, overloading the health care system, and unnecessary anxiety in some patients about their health status. However, studies from the US indicate that high blood pressure at the dentist's office may have other, more relevant, causes and that such patients would benefit from further investigation [23].

The interviewees pointed out the importance of feedback and knowledge of the results of the medical screening. Even those interviewees whose results did not exceed the threshold values for disease risk wanted to receive both oral and written information about their screening results.

Medical screening in dental settings may help individuals with unknown high blood pressure and/or high plasma glucose levels to receive early medical help. This could also be seen in a broader perspective of public health, although the present results are only applicable in their own and possibly similar contexts.

\section{CONCLUSION}

The interviewees experienced the dental care service as providing continuity. They would like to have regular medical screenings at their regular dental appointments to identify risks of cardiovascular diseases and diabetes. However, they expressed that it was important for the dental care staff to have the necessary medical knowledge. They also wanted good cooperations between the dental and health care services, with clear feedback to the patients about both positive and negative results and, when appropriate, referrals to the health care service.

\section{ACKNOWLEDGEMENTS}

The authors would like to thank Comprendo i Tidafors and Linda Schenck for the English language editing.

\section{REFERENCES}

[1] Thomas, M.C., Walker, M.K., Emberson, J.R., Thomson, A.G., Lawlor, D.A., Ebrahim, S., et al. (2005) Prevalence of undiagnosed Type 2 diabetes and impaired fasting glucose in older British men and women. Diabetes Medicine, 22, 789-93. http://dx.doi.org/10.1111/j.1464-5491.2005.01516.x

[2] Rey, A., Thoenes, M., Fimmers, R., Meier, C.A. and Bramlage, P. (2012) Diabetes prevalence and metabolic risk profile in an unselected population visiting pharmacies in Switzerland. Vascular Health and Risk Management, 8, 541-547.

[3] Chobanian, A.V., Bakris, G.L., Black, H.R., et al. (2003) The seventh report of the Joint National Committee on prevention, detection, evaluation, and treatment of high blood pressure: the JNC 7 report. Hypertension, 42, 12061252.

http://dx.doi.org/10.1161/01.HYP.0000107251.49515.c2

[4] Baruch, L. (2004) Hypertension and the elderly: More than just blood pressure control. Journal of Clinical Hypertension, 6, 249-255. http://dx.doi.org/10.1111/j.1524-6175.2004.03307.x

[5] Cowie, C.C., Rust, K.F., Byrd-Holt, D.D., Eberhardt, M.S., Flegal, K.M., Engelgau, M.M., et al. (2006) Prevalence of diabetes and impaired fasting glucose in adults in the US population: National Health and Nutrition Examination Survey 1999-2002. Diabetes Care, 291263-291268.

[6] Charles, M., Simmons, R.K., Williams, K.M., Roglic, G., Sharp, S.J., Kinmonth, A.L., et al. (2012) Cardiovascular risk reduction following diagnosis of diabetes by screening: 1-year results from the ADDITION-Cambridge trial cohort. British Journal of General Practice, 62, 396-402. http://dx.doi.org/10.3399/bjgp12X649070

[7] Kearney, P.M., Whelton, M., Reynolds, K., Muntner, P., Whelton, P.K. and He, J. (2005) Global burden of hypertension: Analysis of worldwide data. Lancet, 365, 217223.

[8] Mathers, C.D., Boerma, T. and Ma Fat, D. (2009) Global and regional causes of death. British Medical Bulletin, 92, 


\section{7-32. http://dx.doi.org/10.1093/bmb/ldp028}

[9] Bahekar, A.A., Singh, S., Saha, S., Molna, J. and Arora, R. (2007) The prevalence and incidence of coronary heart disease is significantly increased in periodontitis: A metaanalysis. American Heart Journal, 54, 830-837. http://dx.doi.org/10.1016/j.ahj.2007.06.037

[10] Kaur, G., Holtfreter, B., Rathmann, W., Schwahn, C., Wallaschofski, H., Schipf, S., et al. (2009) Association between type 1 and type 2 diabetes with periodontal disease and tooth loss. Journal of Clinical Periodontology, 36, 765-774.

http://dx.doi.org/10.1111/j.1600-051X.2009.01445.x

[11] (2012) Swedish social insurance report. http://www.forsakringskassan.se

[12] Listl, S. (2011) Income-related Inequalities in dental service utilization by Europeans aged 50+. Journal of Dental Research, 90, 717-723. http://dx.doi.org/10.1177/0022034511399907

[13] Barasch, A., Safford, M.M., Qvist, V., Palmore, R., Gesko, D. and Gilbert, GH. (2012) Random blood glucose testing in dental practice: A community-based feasibility study from the dental practice-based research network. Journal of the American Dental Association, 143, 262-269.

[14] Sproat, C., Beheshti, S., Harwood, A.N. and Crossbie, D. (2009) Should we screen for hypertension in general dental practice? British Dental Journal, 26, 275-277. http://dx.doi.org/10.1038/sj.bdj.2009.815

[15] Greenberg, B.L., Kantor, M.L., Jiang, S.S. and Glick, M. (2012) Patients' attitudes toward screening for medical conditions in a dental setting. Journal of Public Health Dentistry, 72, 28-35.

http://dx.doi.org/10.1111/j.1752-7325.2011.00280.x

[16] Rosedale, M. and Strauss, S. (2012) Diabetes screening at the periodontal visit: Patient and provider experiences with two screening approaches. International Journal of Dental Hygiene, 10, 250-258. http://dx.doi.org/10.1111/j.1601-5037.2011.00542.x

[17] Friman, G., Wårdh, I., Nilsson, G. and Hultin, M. (2013) Identifying patients in dental settings at risk of cardiovascular disease and diabetes. Cardiovascular System, 1, 5. http://dx.doi.org/10.7243/2052-4358-1-5

[18] Strauss, A. and Corbin, J. (1990) Basics of qualitative research: Grounded theory procedures and tehnicues. Sage Publications Inc., Newbury Park.

[19] Graneheim, U.H. and Lundman, B. (2004) Qualitative content analysis in nursing research: Concepts, procedures and measures to achieve trustworthiness. Nurse Education Today, 24, 105-112. http://dx.doi.org/10.1016/j.nedt.2003.10.001

[20] Greenberg, B.L., Glick, M., Frantsve-Hawley, J. and Kantor, M.L. (2010) Dentist's attitudes toward chairside screening for medical conditions. Journal of the American Dental Association, 141, 52-62.

[21] VanDevanter, N., Combellick, J., Hutchinson, M.K., Phelan, J., Malamud, D. and Shelley, D.A (2012) Qualitative study of patients' attitudes toward HIV testing in the dental setting. Nursing Research and Practice, Article ID: 803169.

[22] Bowyer, V., Sutcliffe, P., Ireland, R., Lindenmeyer, A., Gadsby, R., Graveney, M., et al. (2011) Oral health awareness in adult patients with diabetes: A questionnaire study. British Dental Journal, 23, E12. http://dx.doi.org/10.1038/sj.bdj.2011.769

[23] Hogan, J. and Radhakrishnan, J. (2012) The assessment and importance of hypertension in the dental setting. Dental Clinics of North America, 56, 731-745. http://dx.doi.org/10.1016/j.cden.2012.07.003 